\title{
A genome-wide survey of CD4+ lymphocyte regulatory genetic variants identifies novel asthma genes
}

\section{Citation}

Sharma, Sunita, Xiaobo Zhou, Derek M. Thibault, Blanca E. Himes, Andy Liu, Stanley J. Szefler, Robert Strunk, et al. 2014. "A Genome-Wide Survey of CD4+ Lymphocyte Regulatory Genetic Variants Identifies Novel Asthma Genes." Journal of Allergy and Clinical Immunology 134 (5) (November): 1153-1162. doi:10.1016/j.jaci.2014.04.011.

\section{Published Version}

doi:10.1016/j.jaci.2014.04.011

\section{Permanent link}

http://nrs.harvard.edu/urn-3:HUL.InstRepos:32630755

\section{Terms of Use}

This article was downloaded from Harvard University's DASH repository, and is made available under the terms and conditions applicable to Open Access Policy Articles, as set forth at http:// nrs.harvard.edu/urn-3:HUL.InstRepos:dash.current.terms-of-use\#OAP

\section{Share Your Story}

The Harvard community has made this article openly available.

Please share how this access benefits you. Submit a story.

Accessibility 
() 2014 American Academy of Allergy, Asthma and Immunology. Published by Mosby, Inc. All rights reserved.

Correspondence: Sunita Sharma, MD, MPH, Channing Division of Network Medicine, Brigham and Women's Hospital, 181 Longwood Avenue, Boston, MA 02115, sunita.sharma@ channing.harvard.edu, Tel: 617-525-1234, Fax: 617-525-0958.

\#These authors contributed equally to the work

This is a PDF file of an unedited manuscript that has been accepted for publication. As a service to our customers we are providing this early version of the manuscript. The manuscript will undergo copyediting, typesetting, and review of the resulting proof before it is published in its final citable form. Please note that during the production process errors may be discovered which could affect the content, and all legal disclaimers that apply to the journal pertain. 
${ }^{12}$ University of Southern California, Los Angeles, CA, USA

${ }^{13}$ National Institute of Environmental Health Sciences, National Institutes of Health, Department of Health and Human Services, RTP, NC

${ }^{14}$ Arizona Respiratory Center, University of Arizona, Tucson, AZ, USA

${ }^{15}$ Division of Pulmonary Medicine, Allergy and Immunology, Department of Pediatrics, Children's Hospital of Pittsburgh of UPMC, University of Pittsburgh, Pittsburgh, PA, USA

\section{Abstract}

Background-Genome-wide association studies have yet to identify the majority of genetic variants involved in asthma. We hypothesized that expression quantitative trait locus (eQTL) mapping can identify novel asthma genes by enabling prioritization of putative functional variants for association testing.

Objective-We evaluated 6,706 cis-acting expression-associated variants (eSNP) identified through a genome-wide eQTL survey of CD4+ lymphocytes for association with asthma.

Methods-eSNP were tested for association with asthma in 359 asthma cases and 846 controls from the Childhood Asthma Management Program, with verification using family-based testing. Significant associations were tested for replication in 579 parent-child trios with asthma from Costa Rica. Further functional validation was performed by Formaldehyde Assisted Isolation of Regulatory Elements (FAIRE)-qPCR and Chromatin-Immunoprecipitation (ChIP)-PCR in lung derived epithelial cell lines (Beas-2B and A549) and Jurkat cells, a leukemia cell line derived from T lymphocytes.

Results-Cis-acting eSNP demonstrated associations with asthma in both cohorts. We confirmed the previously-reported association of $O R M D L 3 / G S D M B$ variants with asthma (combined $\mathrm{p}=2.9 \times$ $\left.10^{8}\right)$. Reproducible associations were also observed for eSNP in three additional genes: FADS2 ( $\mathrm{p}=0.002), N A G A(\mathrm{p}=0.0002)$, and $F 13 A 1$ ( $\mathrm{p}=0.0001)$. We subsequently demonstrated that FADS2 mRNA is increased in CD4+ lymphocytes in asthmatics, and that the associated eSNPs reside within DNA segments with histone modifications that denote open chromatin status and confer enhancer activity.

Conclusions-Our results demonstrate the utility of eQTL mapping in the identification of novel asthma genes, and provide evidence for the importance of FADS2, NAGA, and F13Al in the pathogenesis of asthma.

\section{Keywords}

Asthma; CD4+; lymphocytes; regulatory variants; Expression Quantitative Trait Locus (eQTL); Haplotype; Integrative Genomics

\section{Introduction}

Genetic factors influence an individual's asthma susceptibility, with heritability estimates ranging from $36-79 \%{ }^{1}$. Among the various genetic mapping techniques used to identify the genetic determinants of complex diseases, genome-wide association studies (GWAS) have 
been most fruitful. Individual studies and two meta-analyses ${ }^{2,3}$ have identified common sequence variants in at least 10 genes that are consistently associated with asthma in children and adults, including the ZPBP2/GSDMB/ORMDL3 locus (17q), ILIRL1 (2q), IL33 (9p), and TSLP (5q). Though some age- and ethnic-specific trends were noted, these loci are widely reproducible and represent important advances in our understanding of asthma. However, as with virtually all complex diseases, the identified asthma loci explain only a small proportion of the total estimated genetic risk ${ }^{4}$, suggesting that novel approaches are required to identify other genetic variants underlying this "missing heritability."

Expression quantitative trait loci (eQTL) mapping seeks to identify genetic variants that regulate gene expression by considering the distributions of gene transcript abundance for thousands of genes (measured using microarrays) as individual quantitative traits ${ }^{5}$. From more than 20 such studies, expression-associated variants (eSNPs) have been mapped for thousands of expressed genes, explaining, on average, 5 to $15 \%$ of the observed variation in gene expression. Though many eSNP demonstrate wide-spread effects across diverse tissue types, tissue-specific patterns are often observed. Importantly, we and others have demonstrated that, compared to random SNP, identified eSNP are more likely to be associated with complex disease traits 6,7 . In a study of the HapMap lymphoblastoid cell lines (LCLs), Nicolae et al. reported $\sim 2$-fold enrichment for eSNP among diseaseassociated variants ${ }^{6}$. Similarly, in primary peripheral blood CD4+ T-cells, we found the prevalence of eSNP among disease-associated SNPs was $63 \%$ higher than the genome-wide average $^{7}$. These findings suggest that eQTL identification could be leveraged to prioritize SNP for association testing and for localization of functional genetic variants.

Given the central role of the CD4+ lymphocyte in allergic responses and the pathogenesis of asthma $^{8,9}$, we hypothesized that eSNP identified from CD4+ lymphocytes would be enriched for asthma-susceptibility variants, thus enabling identification of novel variants and their associated candidate genes from existing GWAS data. We tested this hypothesis in a study of childhood asthma, the results of which we report here. Some of the results of this study have been previously reported in the form of an abstract ${ }^{10}$.

\section{Methods}

We provide a brief description of the cohorts below, with details in the Online Repository. The Institutional Review Board of Brigham and Women's Hospital approved these studies. Subject recruitment and procedures for the cohorts have been previously described $7,11,12$

\section{The Childhood Asthma Management Program (CAMP): Discovery Population}

The Childhood Asthma Management Program (CAMP) was a multicenter randomized, double-blind, placebo controlled clinical trial established to investigate the effects of inhaled anti-inflammatory asthma medications ${ }^{11}$. Children enrolled in CAMP had mild-moderate persistent asthma based on the demonstration of airway responsiveness to methacholine $\mathrm{PC}_{20}$ (provocative concentration causing a $20 \%$ fall in $\mathrm{FEV}_{1}$ ) less than or equal to $12.5 \mathrm{mg} / \mathrm{ml}$, and at least two of the following: asthma symptoms at least two times per week, the use of inhaled bronchodilator at least twice weekly, or the use of daily asthma medication for at least six months in the year prior to screening ${ }^{11}$. DNA was available for 
403 parent-child trios and an additional 66 singletons of self-reported non-Hispanic white ancestry with mild-to moderate persistent asthma, therefore, 469 self-reported white CAMP subjects were genotyped with Illumina Infinium II HumanHap 550 or Human610W-Quad BeadChips (San Diego, CA). Non-asthmatic controls were selected from 1,533 subjects in the Illumina's iControlIDB resource as previously described ${ }^{13}$. We generated a genetically matched case-control cohort using $\mathrm{GEM}^{14}$, resulting in a final dataset of 359 asthmatic and 846 control subjects, and 547,497 SNPs.

In 200 CAMP participants, we collected peripheral blood CD4+ lymphocyte RNA and performed a genome-wide eQTL analysis for cis-acting eSNP as previously described in $\operatorname{detail}^{7}$. Expression profiling was performed using Illumina Human Ref8 v3 array. Similar to observations by others, our prior eQTL analysis demonstrated a precipitous fall in the prevalence of cis-acting eQTL away from the target gene locus, with a substantial increase in the false discovery rates when considering variants more than $50 \mathrm{~kb}$ from the transcript ${ }^{6,7}$. Thus, to limit the potential for type I error inflation, we limited our search space to SNPs of frequency $\geq 10 \%$ situated within $50 \mathrm{~kb}$ of the transcript. This analysis resulted in the identification of 6,706 cis-acting eSNPs regulating 1,585 genes ${ }^{7}$. Given our prior studies demonstrating enrichment of susceptibilty variants for eSNP, in this current study we prioritized these 6,706 variants for asthma-association testing in the CAMP cohort. An overview of our study design in shown in Supplemental Figure E1.

\section{CAMP: Asthma-susceptibility eSNP association testing}

Case-control asthma association analysis was performed for the 6,706 eSNP detected in CD4+ lymphocytes using PLINK ${ }^{15}$, with EIGENSTRAT adjustment ${ }^{16}$, and retested in a subset of 403 available parent-child trios using PBAT. Haplotype association testing was conducted using Haploview (for asthma) and haplo.score (for expression traits).

\section{Replication of Genetic Associations in the Genetic Epidemiology of Asthma in Costa Rica Cohort (GACRS)}

Replication studies were performed in 579 parent-child trios recruited as part of the Genetic Epidemiology of Asthma in Costa Rica cohort. Details on subject recruitment and study protocols have been published elsewhere ${ }^{12}$. In brief, children ages 6 to 14 years were included in the study if they had asthma (a physician's diagnosis of asthma and $\geq 2$ respiratory symptoms or asthma attacks in the previous year) and a high probability of having $\geq 6$ great-grandparents born in the Central Valley of Costa Rica, which increased the likelihood that children would be descendants of the founder population of the Central Valley ${ }^{12}$.

Only the variants that demonstrated a nominal association with asthma in CAMP $(\mathrm{p}<0.01)$ were tested for association with asthma susceptibility in the Costa Rican cohort using family-based methods in PBAT. The transmitted to untransmitted ratio ( $\mathrm{T}: \mathrm{U}$ ratio) for the significant associations were identified in PLINK. Results were considered significant when identical associations (i.e. same allele, phenotype, and direction of genetic effect) were identified in both populations. Fisher's combined p-value method was applied to assess the cumulative significance of association across populations ${ }^{17}$. 


\section{Validation: Expression of novel asthma genes between asthmatics and non-asthmatic controls in Asthma BRIDGE}

Expression of the FADS2, NAGA, and F13A1 genes was compared between asthmatic subjects $(n=300)$ and non-asthmatic controls $(n=122)$ based on gene expression profiling in CD4+ lymphocytes from the Asthma BioRepository for Integrative Genomic Exploration (Asthma BRIDGE). Asthma BRIDGE is a multicenter-collaborative effort to develop wellcharacterized translational genomic datasets for asthma in North America ${ }^{18}$. Samples were collected through October 2011 from among more than 14,000 subjects studied by the EVE Consortium, providing broad representation of the North American asthmatic population. Genome-wide gene-expression data (Illumina Human HT-12 v4 array) was generated from asthma-relevant primary cell types, including peripheral blood CD4+ lymphocytes.

Differential expression of FADS2, NAGA, and F13A1 was determined using a linear model adjusted for age, gender, and race using the limma package in Bioconductor ${ }^{19}$.

\section{Functional Validation: Chromatin enrichment studies}

Human Beas-2B (\#CRL-9609, ATCC) and A549 (\#CCL-185, ATCC) cells were cultured in complete DMEM medium, and Jurkat (TIB-152, ATCC) cells were cultured in RPMI 1640 medium, all supplemented with $10 \%$ FBS, penicillin (50 units $/ \mathrm{ml})$, streptomycin $(50 \mathrm{mg} / \mathrm{ml}$ ) and gentamicin $(10 \mu \mathrm{g} / \mathrm{ml})$. Additional details can be found in the online repository.

For FAIRE (Formaldehyde-Assisted Isolation of Regulatory Elements) and Chromatin immunoprecipitation (ChIP) followed by real-time PCR, see details in Online Repository. The sequence of primers used in FAIRE-qPCR and ChIP-qPCR was listed in Supplemental Table E1.

\section{Results}

\section{Asthma association testing of eSNP}

The baseline characteristics of the CAMP and Costa Rican index cases included in this study are presented in Table 1. Baseline characteristics were similar between the CAMP and Costa Rican cohorts including measures of asthma severity and lung function.

Of the 6,706 SNP identified as CD4+ lymphocytes cis-acting expression associated eSNP, 143 were associated with asthma under an additive genetic model in the CAMP cohort in either the case-control or family-based association analyses (Supplemental Table E2). To confirm their associations, we next genotyped these 143 variants in the Costa Rican cohort. Associations were reproduced in this independent, ethnically distinct cohort for multiple variants in four genes (Table 2). Firstly, we were able to replicate the association of the chromosome 17q ORMDL3/GSDML locus with asthma ${ }^{20}$. Specifically, two variants (rs4795405 and rs7216389) were strongly associated with asthma in both cohorts (Fisher's combined $\mathrm{p}$ value $=2.9 \times 10^{-8}$ and $3.4 \times 10^{-7}$, respectively). The $\mathrm{T}$ allele of rs4795405 allele was associated with decreased ORMDL3 expression (Figure 1A) ${ }^{7}$, and confers a decreased risk of asthma in two independent cohorts. As previously reported, these variants reside on a haplotype that includes rs1293623, a functional regulatory polymorphism that alters DNA 
binding affinity with the insulator CTCF, resulting in differential expression of three surrounding genes: ORMDL3, GSDML and $Z P B P 2^{21}$.

We also found consistent association in both cohorts for three loci never previously associated with asthma susceptibility: the Fatty Acid Desaturase locus (FADS1/FADS2) on 11q, N-acetyl galactosaminidase (NAGA) on chromosome 22q, and the factor XIII A subunit (F13A1) locus on chromosome 6p. On chromosome 11q12.2, the minor C allele of rs 174611 (C) is associated with increased expression of two adjacent members of the fatty-acid desaturase gene cluster (FADS1 and $F A D S 2$, FDR p=0.001 and 0.0007, respectively, Figure 1B). The $\mathrm{C}$ allele of this variant confers an increased risk of asthma in both CAMP and Costa Rica (Fisher's combined $\mathrm{p}$ value $=0.002$ ). On chromosome 22q13.2, the $\mathrm{C}$ allele of SNP rs2413669, located $\sim 40 \mathrm{~kb}$ upstream of the transcription start site of the alpha-Nacetylgalactosaminidase precursor gene (NAGA), was associated with decreased $N A G A$ expression (FDR $\mathrm{p}=0.0003$, Figure 1C), as well as with decreased odds of asthma in both cohorts (Fisher's combined $\mathrm{p}=0.0002$ ). On chromosome 6p25.1, the $\mathrm{T}$ allele of variant rs11243081 was associated with increased expression of the coagulation factor XIII A1 gene (F13Al, FDR p =0.0009, Figure 1D), as well as with increased asthma susceptibility in both cohorts (Fisher's combined $\mathrm{p}=0.0001$ ). Of note, the magnitudes of the effect for each of these genetic variants on asthma susceptibility were similar in both cohorts.

\section{Haplotype testing of asthma-associated regulatory loci}

Using genome-wide genotypic data available in CAMP subjects, we next tested haplotype blocks for each of the three novel genes identified in this study for association with gene expression and asthma susceptibility. Figure 2 illustrates the results of the association analyses of the $F A D S 2$ locus. SNP rs968567, located in a conserved promoter region of the FADS2 locus, was associated with FADS2 expression $\left(\mathrm{p}=10^{-15}\right.$ ), explaining $30 \%$ of its variance. In addition, the minor allele of SNP rs174611, which is associated with asthma in CAMP and Costa Rica, explains $11 \%$ of the variance in FADS2 gene expression ( $\mathrm{p}=0.0007$ ) and $5.3 \%$ of the expression in FADS1 ( $\mathrm{p}=0.03$ ). Figure 3a shows the haplotype structure of the FADS2 locus. The T allele of SNP rs968567 uniquely tags a common haplotype in block 2 (H2), which is observed in $18.1 \%$ of the subjects. SNPs rs 174627 and rs174611 are in linkage disequilibrium (LD) with SNP rs968567; all three of these variants and the FADS $\mathrm{H} 2$ haplotype are associated with asthma susceptibility in the CAMP cohort ( $\mathrm{p}=0.001$ to 3 $\times 10^{-4}$ ). Furthermore, as seen in Figure 3b, haplotype 2 is associated with increased FADS2 expression $\left(\mathrm{p}=10^{-10}\right)$, suggesting that this is a functional regulatory haplotype in the FADS region.

In contrast, the genomic region of eQTL association for F13Al is relatively narrow (Supplemental Figure E2) despite of its relative large gene size: 177kb. Although there are three haplotype blocks demonstrating eQTL association (Supplemental Table E4), only one block (Block 9) is strongly associated with both F13A expression (p=0.0007) and also with asthma $(\mathrm{p}=0.003)$.

In the NAGA association analysis, the minor allele of SNP rs2413669 explains 6\% of the variation in expression of $N A G A$ (Supplemental Figure E3, p=0.0003). However, unlike the $F A D S$ and F13A1 loci, haplotype block analysis did not help localize the functional variant: 
haplotype blocks in NAGA were not significantly associated with either asthma or NAGA expression ( $\mathrm{p} \searrow 0.05$ ), suggesting the functional regulatory variant likely resides on more than one haplotype, in LD with the asthma-associated eSNP rs2413669.

\section{Validation: Differential FADS2 expression in asthma in Asthma BRIDGE}

Having demonstrated that variants that regulate gene expression in CD4+ lymphocytes were reproducibly associated with asthma, we next assessed whether the expression of target genes were similarly correlated with asthma status. We therefore assessed the expression of FADS2, NAGA and F13AI in 300 asthma cases and 122 non-asthmatic controls participating in Asthma BRIDGE with available expression data in peripheral blood CD4+ lymphocytes (see Supplemental Table E3 for baseline characteristics of the cohort used for this analysis). Of the three genes evaluated, FADS2 mRNA expression was significantly increased in asthmatics compared to non-asthmatic controls ( $\mathrm{p}=0.003$, Figure 4). FADSI expression was also modestly increased in asthma cases compared to controls $(\mathrm{p}=0.04)$, and a trend towards increased NAGA expression was also observed in asthma cases $(\mathrm{p}=0.05)$. There was no evidence of asthma-related differential expression of $F 13 A 1(\mathrm{p}=0.60)$.

\section{Functional Validation: Open chromatin enrichment studies}

The expression-associated regulatory variants identified by eQTL mapping are often surrogates for functional regulatory variation situated in neighboring regulatory DNA regions $^{22,23}$. However, given that the $F A D S 2$ rs 968567 regulatory variant uniquely tags the asthma-associated $\mathrm{H} 2$ haplotype, and the $N A G A$ rs2413669 variant (but not NAGA haplotypes) is associated with asthma and NAGA expression, it is possible that these two disease associated eSNPs are not merely surrogates or tagging variants, but actually represent the functional variants regulating the target gene expression thus driving the asthma association. To assess this, we first screened for active regulatory activity at the three loci by FAIRE-qPCR, a method used to detect open chromatin regions devoid of nucleosomes ${ }^{24}$. Given that the eQTL analysis was performed in CD4+ T cells, we chose the Jurkat acute $\mathrm{T}$ cell leukemia cell line, in addition to two respiratory epithelial cell lines: Beas-2B (human bronchial epithelial cells) and A549 (human alveolar type II-like pneumocyte). Three SNPs that showed association with asthma in each region were chosen for open chromatin assessments in these cell lines. As shown in Figure 5, the FADS2 associated SNP rs968567 showed 15 fold enrichment of FAIRE signals in A549 and Jurkat cells and $\sim 5$ fold enrichment in Beas-2B cells compared to the negative control region ( $\mathrm{p}<0.01$, unpaired $t$ test), consistent with previous finding that rs 968567 is a functional SNP with differential binding to transcription factor ELK- ${ }^{25}$. Furthermore, in the NAGA association region, we observed strong enrichment of FAIRE signals near rs1801311 in Jurkat cells as well as in Beas-2B and A549 cells. In contrast, FAIRE signals in SNPs around the F13Al region were relatively weak, suggesting these SNPs are not themselves functional, but rather tag the causal variants within block 9 .

Epigenetic modifications on histone tails of nucleosomes usually indicate active or repressive transcriptional regulations ${ }^{26}$. To further confirm our finding about potential regulatory SNPs indicated by FAIRE, we applied ChIP-PCR with antibodies targeting two enhancer markers H3K4Me1 (indicating enhancer regions) and H3K27Ac (indicating active 
enhancer and/or promoter regions) in the FADS2 and NAGA regions in Beas-2B, A549 and Jurkat cells (Figure 6). Consistent with FAIRE enrichment signals, H3K27Ac showed significant enrichment at two SNPs we tested in FADS2 and NAGA regions in almost all three cell lines, indicating active regulatory elements are contained in both the NAGA and FADS2 regions near eSNPs.

\section{Discussion}

Although GWAS of complex traits have offered insights into the genetic underpinnings of complex diseases like asthma, the discovered variants explain only a fraction of the genetic contribution to such diseases ${ }^{4}$. In some part, this is likely due to the stringent multiple comparisons burden imposed when testing millions of (mostly functionless) variants. Strategies that guide prioritization of functional genetic markers for testing can address this issue. We and others have demonstrated that eSNP are more likely to be disease-associated variants ${ }^{6,7}$ suggesting eQTL mapping as a promising strategy. Using asthma as a model, we sought to evaluate this possibility by testing cis-acting regulatory variants previously identified from an eQTL mapping study of peripheral blood CD4+ lymphocytes for association with asthma in two well-characterized populations. Using this integrative genomic approach in CAMP subjects, we have not only replicated the association of the $17 \mathrm{q}$ ORMDL3/GSDMB locus for association with asthma in two childhood asthma cohorts, but have also defined three novel candidate loci. These later associations did not emerge from prior studies as their nominal association p-values were below the threshold for multiple comparisons correction. Though our application of a functional prioritization strategy using eQTL data led to consideration and successful independent replication of these loci in the Costa Rican cohort, supporting application of such strategies for identification of novel disease candidate genes, they will require follow-up replication testing to assess whether the results are generalizable. We also recognize that the relatively small size of our test and replication cohorts may have precluded identification of additional asthma variants due to limits in statistical power. Application of eQTL approaches to larger populations is warranted. In addition, consideration should be extended beyond cis-acting regulatory variants once adequately powered studies identify validated, reproducible trans-acting eQTLs.

Of three novel genes identified in this study, the greatest biological and epidemiological support is provided for $F A D S 2$ and the fatty acid desaturase gene cluster on chromosome 11. The FADS1 and FADS2 genes respectively encode for $\triangle 5$ - and $\Delta 6$-desaturase - enzymes that are critical for long chain poly-unsaturated fatty acid (PUFA) biosynthesis, which are the precursors of eicosanoid mediators that are critical to the development and resolution of allergic inflammation ${ }^{27,28}$. PUFAs are synthesized from two essential fatty acids: linoleic acid (LA;18:2n-6) and alpha-linolenic acid (ALA; 18:3n-3). Desaturase enzymes introduce double bonds between defined carbons of the fatty acyl chain. $\Delta 6$-desaturase (FADS2) catalyzes the first rate-limiting step in long chain PUFA biosynthesis by causing desaturation of LA and ALA. In our study, we demonstrate association of eSNPs in FADS2 with asthma in two cohorts, and localize the most robust associations to a haplotype-tagging variant - rs968567, situated in the promoter of FADS2 that is strongly associated with $F A D S 2$ (and to a lesser degree $F A D S 1$ ) expression. We also detected increased expression of 
FADS2 in peripheral blood CD4+ lymphocytes of asthmatics in a large population sample, consistent with increased expression of FADS2 conferred by asthma risk allele in this locus. In addition, rs968567 demonstrates strong enrichment for open chromatin status in both lymphocyte and bronchial epithelial cell lines. In hepatocytes, this same variant exhibits differential binding of the ELK1 transcription factor ${ }^{25}$. This variant, and others in strong LD with it, have been strongly associated with circulating PUFA ${ }^{29}$, total cholesterol and highdensity lipoprotein, and omega-3 fatty acid levels ${ }^{30}$. Perhaps most pertinent in the context of asthma pathogenesis, a recent GWAS study in a general population sample ${ }^{29}$ found this FADS2 promoter variant to explain $19 \%$ of the population variance in serum levels of arachadonic acid (AA) - the precursor for pro- and anti-inflammatory prostaglandins and leukotrienes ${ }^{27}$.

Due to their roles in the production of pro-inflammatory and anti-inflammatory eicosanoids, and evidence for PUFAs in the alteration of T-cell antigen presentation ${ }^{31}$, others have investigated the role of FADS1/FADS2 polymorphism in atopic disease, with variable results. In one candidate-gene birth cohort study of 879 children, FADS variants that were associated with PUFA and AA serums levels were also associated with increased eczema risk $^{32}$. In contrast, these same variants were inversely associated with eczema and allergic rhinitis in an adult population ${ }^{33}$. In addition, recent work by Standl and colleagues demonstrated that genetic variants in the FADS cluster modify the effect of breastfeeding on the development of asthma with the lowest risk noted in children who were exclusively breast fed for the first three months of life ${ }^{34}$. Although the biologic mechanism underlying this association is unclear, the authors speculate that carriers of the minor allele have lower fatty acid metabolism and, thus, less arachadonic acid levels ${ }^{34}$. Though replication of these interactions have yet to be reported, if true, such interaction could represent an important modifier of our observed associations between FADS2 genotype and asthma susceptibility, posing greater challenges to replication in additional populations. Although none of these studies focused exclusively on asthma, making direct comparisons with our initial observations difficult, assuming a direct correlation between asthma and risk for other atopic diseases, our findings are consistent with those in the pediatric cohort, with high FADS2 expression associated with increased asthma and atopic risk. The associations may be age dependent (explaining the different findings in adults), or modified by dietary PUFA intake. While these possibilities must be tested in other populations, the evidence presented here, together with that from prior studies support FADS2 as a biologically plausible asthmasusceptibility gene.

In contrast to $F A D S 2$, the roles of $N A G A$ and $F 13 A 1$ in asthma pathogenesis are less clear. $N A G A$ is a lysosomal glycohydrolase that cleaves the alpha- $\mathrm{N}$-acetylgalactosaminyl moieties from glycol-conjugates. NAGA has been implicated as part of the carbohydrate-mediated mechanism of mast cell adhesion to the bronchial epithelium ${ }^{35}$. Treatment of mast cells of endo-a-N-acytelgalactosaminidase, an enzyme that cleaves disaccharides on the cell surface of the mast cell, results in a significant reduction of mast cell adhesion to bronchial epithelium and changes in airway responsiveness ${ }^{35}$. Moreover, a guinea pig model demonstrated increased NAGA released from bronchoalveolar macrophages in animals with increased airways responsiveness following high ozone exposure ${ }^{36}$. Though speculative, 
given the central role of macrophages and mast cell degranulation in bronchoconstriction, mucus secretion, and airway inflammation in asthmatics ${ }^{37}$, the asthma-associated $N A G A$ eSNP may influence asthma risk through altered glycohydrolase activity.

F13A1 encodes the alpha subunit of factor X111, the last enzyme generated in the blood coagulation cascade, stabilizing blood clots by cross-linking fibrin. $F 13 A l$ has also been implicated in the inflammatory cascade and in atopy ${ }^{38}$. When stimulated with dust-mite antigen, peripheral blood mononuclear cells from dust-mite allergic patients demonstrate increased production of $F 13 A I^{39}$. F13Al has also been implicated as a susceptibility locus for obesity ${ }^{40}$. Epidemiologic data demonstrates a consistent link between asthma and obesity $^{41}$, with apparent shared genetic determinants ${ }^{42}$. How F13Al regulatory variation confers susceptibility to asthma, and whether $F 13 \mathrm{Al}$ represents a shared genetic determinant of both asthma and obesity, remains unclear. In addition to replication in additional asthma populations, further characterization of the functional impact of these variants in model systems will be needed to resolve these questions.

Though we have demonstrated the utility of eQTL mapping for the identification of asthmasusceptibility variants, our studies were limited in scope, particularly in regards to the narrow focus on cis-acting regulatory variation in only one cell type - the CD4+ lymphocyte. Although this cell type is relevant to allergic cytokine profiles and asthma, it is only one of many cell types of potential interest. Given that a substantial proportion of cisacting regulatory variants demonstrate tissue-specific effects, we have likely overlooked some functional variation specific to other relevant cell types, including antigen presenting cells, granulocytes, airway smooth muscle and bronchial epithelium. A recent eQTL study in human lung tissue samples provides complementary evidence at the $17 \mathrm{q}$ locus, suggesting a potential role for altered expression of GSDMA, in addition to the altered ORMDL3 and GSDMB expression noted by us and others in lymphocytic lines ${ }^{43}$. Thus, we view these initial efforts as the first step of a more integrative approach to disease gene mapping that considers eQTL variation across multiple tissue types, in diverse patient populations, and under disease-relevant environmental exposures and that also considers other functional annotations, including chromatin modification, $\mathrm{CpG}$ methylation differences, and other epigenetic modifications ${ }^{44}$. Such comprehensive, more holistic approaches, combined with powerful systems based analytical tools, should provide a more complete picture of the genetic landscape in asthma.

In summary, we provide new evidence in support of FADS2, NAGA, and F13A1 as asthmasusceptibility loci. Similar to variants previously identified through GWAS and other genetic approaches, the relatively modest effect sizes conferred by these loci limit their clinical utility as diagnostic or prognostic markers. Instead, our observations motivate prioritization of these loci and their related pathways for further investigation. Of these, we find strongest support for a common promoter polymorphism in the FADS2 gene, which regulates FADS2 expression, is associated with asthma and allergic phenotypes, and has been previously shown to be the major genetic determinant of plasma arachadonic acid levels - the major precursor of asthma-relevant eicosanoids. Though replication of these associations in additional populations is warranted, these findings should prompt revisiting this important pathway as a potential therapeutic asthma target. 


\section{Supplementary Material}

Refer to Web version on PubMed Central for supplementary material.

\section{Acknowledgments}

We thank all subjects for their ongoing participation in this study. We acknowledge the CAMP investigators and research team, supported by NHLBI, for collection of CAMP Genetic Ancillary Study data. Special thanks to Anne Plunkett, Teresa Concordia, Debbie Bull, Denise Rodgers, and D. Sundstrom for their assistance with sample collection; to Huiqing Yin-DeClue, Ph.D, Michael McLane and Chris Allaire for their assistance with T cell isolations and RNA preparation; and to Ankur Patel for his assistance running the microarrays.

All work on data collected from the CAMP Genetic Ancillary Study was conducted at the Channing Laboratory of the Brigham and Women's Hospital under appropriate CAMP policies and human subject protections. This work is supported by grant R01 HL086601 and RC2 HL101543 from the National Heart, Lung and Blood Institute, National Institutes of Health (NIH/NHLBI). The CAMP Genetics Ancillary Study is supported by U01 HL075419, U01 HL65899, P01 HL083069, and through the Colorado CTSA grant 1 UL1 RR025780 from the National Institutes of Health (NIH) and National Center for Research Resources (NCRR). BEH was supported by NIH K99 HL105663. S.S. receives additional support from K08 HL096833 from NIH/NHLBI. Additional support provided by NIH P01ES011627 (PI: F. Gilliland). Supported in part by the Division of Intramural Research, National Institute of Environmental Health Sciences, NIH.

Funding: R01 HL086601, RC2 HL101543, R37 HL066289, and K08 HL096833

\section{Abbreviations}

CAMP Childhood Asthma Management Program

ChIP Chromatin-Immunoprecipitation-PCR

eQTL Expression quantitative trait loci

eSNP Expression-associated variant

F13A1 Factor XIII, A1

FADS1 Fatty Acid Desaturase 1

FADS2 Fatty Acid Desaturase 2

FAIRE Formaldehyde Assisted Isolation of Regulatory Elements-qPCR

GACRS Genetics of Asthma in Costa Rica Study

GWAS Genome-wide association studies

NAGA N-acetyl-alpha-D-Galactosaminidase

SNP Single nucleotide polymorphism

\section{Appendix}

\section{The Asthma BRIDGE Consortium}

\section{Asthma BRIDGE Data Coordinating Center}

Childhood Asthma Management Program (CAMP) Genetics Ancillary Study-

Brigham and Women's Hospital, Harvard Medical School, Boston MA 
Benjamin A. Raby, MD, MPH (PI), Scott T. Weiss, MD, MSc (PI); Vincent Carey, PhD; WeiliangQiu, PhD; Roxanne Kelly, BSc; Jody Sylvia Senter, MS; John Ziniti, BSc; Diana Tubbs; Brooke Schumann; Damien Croteau-Chonka, PhD.

\section{Childhood Asthma Research and Education (CARE) Network-Arizona}

Respiratory Center, University of Arizona (Coordinating Center)

Fernando Martinez, MD, (PI); Wayne Morgan, MD; James Goodwin, PhD; Anthony Bosco, $\mathrm{PhD}$ (also at Telethon Institute for Child Health Research, Centre for Child Health Research, University of Western Australia); Monica Vasquez, MPH; Rosemary Weese, RN; Silvia Lopez, RN; Jesus Wences, BS; Monica Varela, LPN; Janette Priefert; Katherine Chee; Samira Ehteshami, BS; Xiaobing Liu, BS.

National Jewish Health, Denver CO

Andy Liu, MD (PI); Allison Schlitz, BA; Julie Henley, CCRC; D. A. Sundström, BA; Melanie Phillips, BS; Sakari Graves, BA; Phillip Lopez, BS; Liliana Soto, CRC.

University of Wisconsin-Madison, Maddison WI

Robert F. Lemanske, Jr., MD (PI); Theresa W. Guilbert, MD; Sarah Sund, BS, MT (ASCP); Tiffany Huard, BS, CCRC; Elizabeth A. Schwantes, BS;

Washington University School of Medicine, St. Louis MO

Robert C. Strunk, MD (PI); Tina Norris (was Oliver) CCRP, CRT; Wanda Caldwell, RRT; Cynthia Moseid;

Chicago Asthma Genetics (CAG) Study-University of Chicago, Chicago IL

Carole Ober, PhD (PI); Dan Nicolae, PhD; Julian Solway, MD; Jerry Krishnan, MD, PhD; White Steve, MD; Kyle Hogarth, MD; John McConville, MD; Rebecca Anderson, MS; JyotsnaSudi, MS; Lourdes Norwick, BSN, RN; Myers Rachel, PhD.

\section{Genomic Research on Asthma in the African Diaspora (GRAAD)—Johns} Hopkins University, Baltimore MD

Kathleen C. Barnes, PhD (PI); Nadia Hansel, MD, MPH; John T. Schroeder, PhD; Chris Cheadle, PhD; Rasika A. Mathias, ScD; Alan E. Berger, PhD; Jinshui Fan, MD, PhD; CandelariaVergara, MD, MSc; Cassandra Foster; MeherBoorgula, RiaBarkataki, Li Gao, MD, PhD; Joseph Potee, MS; Terri H. Beaty, PhD; Ingo Ruczinski, PhD; Jeff Leek, PhD

Mexico City Childhood Asthma Study (MCCAS)—National Institute of Environmental Health Sciences, National Institute of Public Health of Mexico, Hospital Infantil de Mexico Federico Gomez

Stephanie J London, MD, DrPH; Albino BarrazaVillarreal , MSc, DrPH; Leticia Hernandez Cadena, MSc, DrPH; Efrain Navarro Olivos, MD, MSc; Isabelle Romieu, MD, MPH, DrS; 
Juan Jose SienraMonge, MD; Blanca Estela del Río Navarro, MD; Isabelle García; Cynthia Hernandez.

Children's Health Study (CHS)—University of Southern California, Los Angeles CA

Frank D. Gilliland, MD, PhD (PI); Talat Islam, MBBS, PhD; Carrie V. Breton, ScD; Muhammad T. Salam, MBBS, PhD; Kimberly D. Siegmund, PhD; Xinhui Wang, MS; Xia Li, MS.

\section{References}

1. Sibbald B, Horn ME, Gregg I. A family study of the genetic basis of asthma and wheezy bronchitis. Archives of disease in childhood. 1980; 55:354-357. [PubMed: 7436470]

2. Torgerson DG, Ampleford EJ, Chiu GY, Gauderman WJ, Gignoux CR, Graves PE, et al. Metaanalysis of genome-wide association studies of asthma in ethnically diverse North American populations. Nature genetics. 2011; 43:887-892. [PubMed: 21804549]

3. Moffatt MF, Gut IG, Demenais F, Strachan DP, Bouzigon E, Heath S, et al. A large-scale, consortium-based genomewide association study of asthma. The New England journal of medicine. 2010; 363:1211-1221. [PubMed: 20860503]

4. Manolio TA, Collins FS, Cox NJ, Goldstein DB, Hindorff LA, Hunter DJ, et al. Finding the missing heritability of complex diseases. Nature. 2009; 461:747-753. [PubMed: 19812666]

5. Schadt EE, Monks SA, Drake TA, Lusis AJ, Che N, Colinayo V, et al. Genetics of gene expression surveyed in maize, mouse and man. Nature. 2003; 422:297-302. [PubMed: 12646919]

6. Nicolae DL, Gamazon E, Zhang W, Duan S, Dolan ME, Cox NJ. Trait-associated SNPs are more likely to be eQTLs: annotation to enhance discovery from GWAS. PLoS genetics. 2010; 6:e1000888. [PubMed: 20369019]

7. Murphy A, Chu JH, Xu M, Carey VJ, Lazarus R, Liu A, et al. Mapping of numerous diseaseassociated expression polymorphisms in primary peripheral blood CD4+ lymphocytes. Human molecular genetics. 2010; 19:4745-4757. [PubMed: 20833654]

8. Gu W, Xu W, Ding T, Guo X. Fringe controls naive CD4(+)T cells differentiation through modulating notch signaling in asthmatic rat models. PLoS One. 2012; 7:e47288. [PubMed: 23071776]

9. Busse M, Krech M, Meyer-Bahlburg A, Hennig C, Hansen G. ICOS mediates the generation and function of $\mathrm{CD} 4+\mathrm{CD} 25+\mathrm{Foxp} 3+$ regulatory $\mathrm{T}$ cells conveying respiratory tolerance. Journal of immunology. 2012; 189:1975-1982.

10. Sharma, SMA.; Himes, BE.; Howrylak, J.; Avila, L.; Soto-Quiros, M.; Celedon, JC.; Carey, VJ.; Raby, BA. American Society of Human Genetics. Washington DC, USA; 2010. eQTL mapping in peripheral blood CD4+ lymphocytes identifies replicable novel asthma susceptibility loci, augmenting standard genome-wide association testing (abstract).

11. The Childhood Asthma Management Program (CAMP): design, rationale, and methods. Childhood Asthma Management Program Research Group. Control Clin Trials. 1999; 20:91-120. [PubMed: 10027502]

12. Hunninghake GM, Soto-Quiros ME, Avila L, Ly NP, Liang C, Sylvia JS, et al. Sensitization to Ascaris lumbricoides and severity of childhood asthma in Costa Rica. J Allergy Clin Immunol. 2007; 119:654-661. [PubMed: 17336615]

13. Himes BE, Hunninghake GM, Baurley JW, Rafaels NM, Sleiman P, Strachan DP, et al. Genomewide association analysis identifies PDE4D as an asthma-susceptibility gene. Am J Hum Genet. 2009; 84:581-593. [PubMed: 19426955]

14. Luca D, Ringquist S, Klei L, Lee AB, Gieger C, Wichmann HE, et al. On the use of general control samples for genome-wide association studies: genetic matching highlights causal variants. Am J Hum Genet. 2008; 82:453-463. [PubMed: 18252225] 
15. Purcell S, Neale B, Todd-Brown K, Thomas L, Ferreira MA, Bender D, et al. PLINK: a tool set for whole-genome association and population-based linkage analyses. Am J Hum Genet. 2007; 81:559-575. [PubMed: 17701901]

16. Price AL, Patterson NJ, Plenge RM, Weinblatt ME, Shadick NA, Reich D. Principal components analysis corrects for stratification in genome-wide association studies. Nat Genet. 2006; 38:904909. [PubMed: 16862161]

17. Fisher R. Combining independent tests of significance. Am Stat. 1948; 2

18. Qiu W, Koppelman GH, Carey VJ, Ziniti J, London S, Barnes KC, et al. Expression quantitative trait locus (eqtl) mapping in diverse populations and cell types identifies numerous asthmaassociated regulatory variants. American Thoracic Society International Conference. Philadelphia. 2012:A2521.

19. Smyth GK. Linear models and empirical bayes methods for assessing differential expression in microarray experiments. Stat Appl Genet Mol Biol. 2004; 3 Article3.

20. Moffatt MF, Kabesch M, Liang L, Dixon AL, Strachan D, Heath S, et al. Genetic variants regulating ORMDL3 expression contribute to the risk of childhood asthma. Nature. 2007; 448:470-473. [PubMed: 17611496]

21. Verlaan DJ, Berlivet S, Hunninghake GM, Madore AM, Lariviere M, Moussette S, et al. Allelespecific chromatin remodeling in the ZPBP2/GSDMB/ORMDL3 locus associated with the risk of asthma and autoimmune disease. Am J Hum Genet. 2009; 85:377-393. [PubMed: 19732864]

22. Stranger BE, Montgomery SB, Dimas AS, Parts L, Stegle O, Ingle CE, et al. Patterns of cis regulatory variation in diverse human populations. PLoS genetics. 2012; 8:e1002639. [PubMed: 22532805]

23. Loo LW, Cheng I, Tiirikainen M, Lum-Jones A, Seifried A, Dunklee LM, et al. cis-Expression QTL analysis of established colorectal cancer risk variants in colon tumors and adjacent normal tissue. PLoS One. 2012; 7:e30477. [PubMed: 22363440]

24. Giresi PG, Kim J, McDaniell RM, Iyer VR, Lieb JD. FAIRE (Formaldehyde-Assisted Isolation of Regulatory Elements) isolates active regulatory elements from human chromatin. Genome Res. 2007; 17:877-885. [PubMed: 17179217]

25. Lattka E, Eggers S, Moeller G, Heim K, Weber M, Mehta D, et al. A common FADS2 promoter polymorphism increases promoter activity and facilitates binding of transcription factor ELK1. Journal of lipid research. 2010; 51:182-191. [PubMed: 19546342]

26. Schmid CD, Bucher P. ChIP-Seq data reveal nucleosome architecture of human promoters. Cell. 2007; 131:831-832. author reply 2-3. [PubMed: 18045524]

27. Calder PC. Polyunsaturated fatty acids, inflammatory processes and inflammatory bowel diseases. Mol Nutr Food Res. 2008; 52:885-897. [PubMed: 18504706]

28. Martinelli N, Girelli D, Malerba G, Guarini P, Illig T, Trabetti E, et al. FADS genotypes and desaturase activity estimated by the ratio of arachidonic acid to linoleic acid are associated with inflammation and coronary artery disease. Am J Clin Nutr. 2008; 88:941-949. [PubMed: 18842780]

29. Tanaka T, Shen J, Abecasis GR, Kisialiou A, Ordovas JM, Guralnik JM, et al. Genome-wide association study of plasma polyunsaturated fatty acids in the InCHIANTI Study. PLoS Genet. 2009; 5:e1000338. [PubMed: 19148276]

30. Chambers JC, Zhang W, Sehmi J, Li X, Wass MN, Van der Harst P, et al. Genome-wide association study identifies loci influencing concentrations of liver enzymes in plasma. Nat Genet. 43:1131-1138. [PubMed: 22001757]

31. Sanderson P, MacPherson GG, Jenkins CH, Calder PC. Dietary fish oil diminishes the antigen presentation activity of rat dendritic cells. J Leukoc Biol. 1997; 62:771-777. [PubMed: 9400818]

32. Rzehak P, Thijs C, Standl M, Mommers M, Glaser C, Jansen E, et al. Variants of the FADS1 FADS2 gene cluster, blood levels of polyunsaturated fatty acids and eczema in children within the first 2 years of life. PLoS One. 2010; 5:e13261. [PubMed: 20948998]

33. Schaeffer L, Gohlke H, Muller M, Heid IM, Palmer LJ, Kompauer I, et al. Common genetic variants of the FADS1 FADS2 gene cluster and their reconstructed haplotypes are associated with the fatty acid composition in phospholipids. Hum Mol Genet. 2006; 15:1745-1756. [PubMed: 16670158] 
34. Standl M, Sausenthaler S, Lattka E, Koletzko S, Bauer CP, Wichmann HE, et al. FADS gene cluster modulates the effect of breastfeeding on asthma Results from the GINIplus and LISAplus studies. Allergy. 2012; 67:83-90. [PubMed: 21933193]

35. Sanmugalingam D, Wardlaw AJ, Bradding P. Adhesion of human lung mast cells to bronchial epithelium: evidence for a novel carbohydrate-mediated mechanism. J Leukoc Biol. 2000; 68:3846. [PubMed: 10914488]

36. Lew DB, Chodimella V, Murlas CG. Guinea pig ozone-induced airway hyperreactivity is associated with increased $\mathrm{N}$-acetyl-beta-D-glucosaminidase activity in bronchoalveolar lavage fluid. Lung. 1990; 168:273-283. [PubMed: 2126835]

37. Okayama Y, Bradding P, Tunon-de-Lara JM, Holgate ST, Church MK. Cytokine production by human mast cells. Chem Immunol. 1995; 61:114-134. [PubMed: 7662140]

38. Marioni RE, Deary IJ, Murray GD, Fowkes FG, Price JF. Associations between polymorphisms in five inflammation-related genes and cognitive ability in older persons. Genes, brain, and behavior. 2010; 9:348-352.

39. Fukuda T, Mochida S, Fukushima Y, Makino S. Detection of allergen-induced genes in peripheral blood mononuclear cells of patients with allergic asthma using subtractive hybridization. J Allergy Clin Immunol. 1995; 96:1076-1082. [PubMed: 8543765]

40. Naukkarinen J, Surakka I, Pietilainen KH, Rissanen A, Salomaa V, Ripatti S, et al. Use of genomewide expression data to mine the "Gray Zone" of GWA studies leads to novel candidate obesity genes. PLoS genetics. 2010; 6:e1000976. [PubMed: 20532202]

41. Litonjua AA, Gold DR. Asthma and obesity: common early-life influences in the inception of disease. J Allergy Clin Immunol. 2008; 121:1075-1084. quiz 85-6. [PubMed: 18378287]

42. Melen E, Himes BE, Brehm JM, Boutaoui N, Klanderman BJ, Sylvia JS, et al. Analyses of shared genetic factors between asthma and obesity in children. The Journal of allergy and clinical immunology. 2010; 126:631-637. e1-8. [PubMed: 20816195]

43. Hao K, Bosse Y, Nickle DC, Pare PD, Postma DS, Laviolette M, et al. Lung eQTLs to help reveal the molecular underpinnings of asthma. PLoS genetics. 2012; 8:e1003029. [PubMed: 23209423]

44. Ward LD, Kellis M. Interpreting noncoding genetic variation in complex traits and human disease. Nature biotechnology. 2012; 30:1095-1106. 


\section{Key Messages}

- Integrative genomic approaches including expression quantitative trait loci (eQTL) mapping can be used to prioritize genetic variants for disease susceptibility testing.

- Using a genome-wide survey of regulatory genetic variants in peripheral blood CD4+ lymphocytes sampled from subjects with asthma, we identified novel asthma susceptibility loci, including FADSI/FADS2, NAGA, and F13A1.

- Functional variants can be further localized through a combination of eQTL mapping with assessments of chromatin status and modifications nearby eQTL SNPs. 
A. Association of rs4795405 with ORMDL3 expression

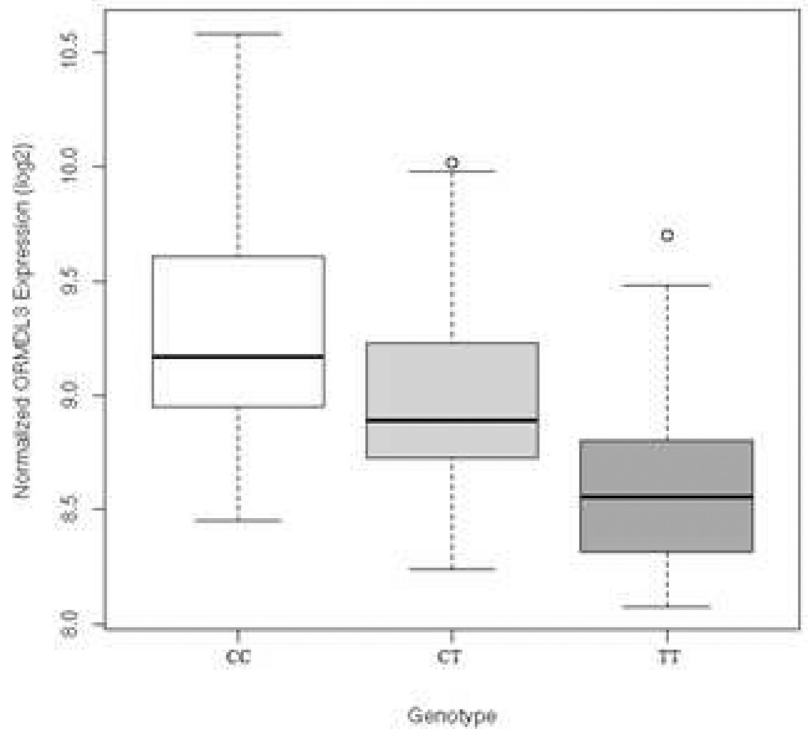

C. Association of rs2413669 with NAGA expression

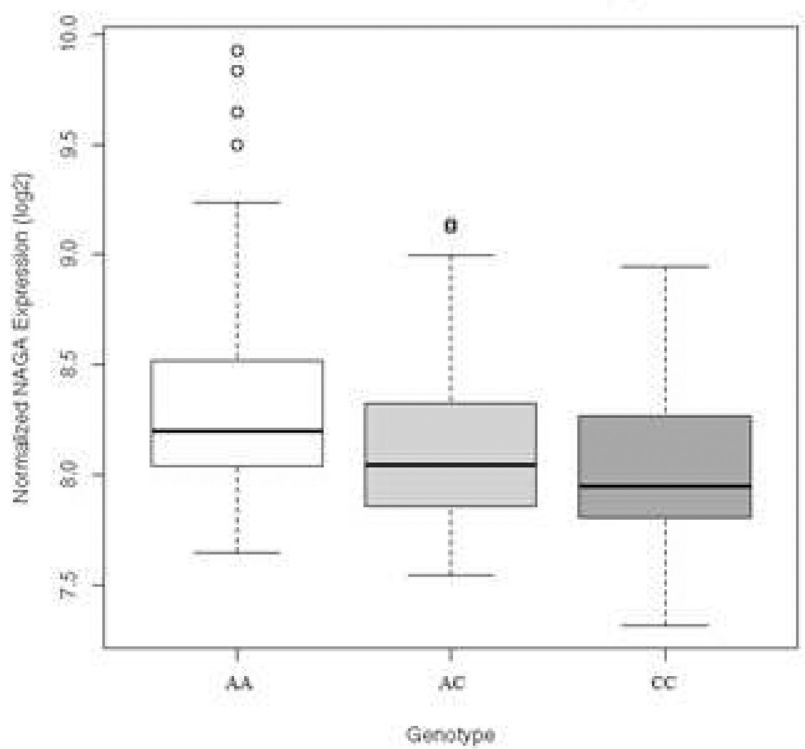

B. Association of rs174611 with FADS2 expression

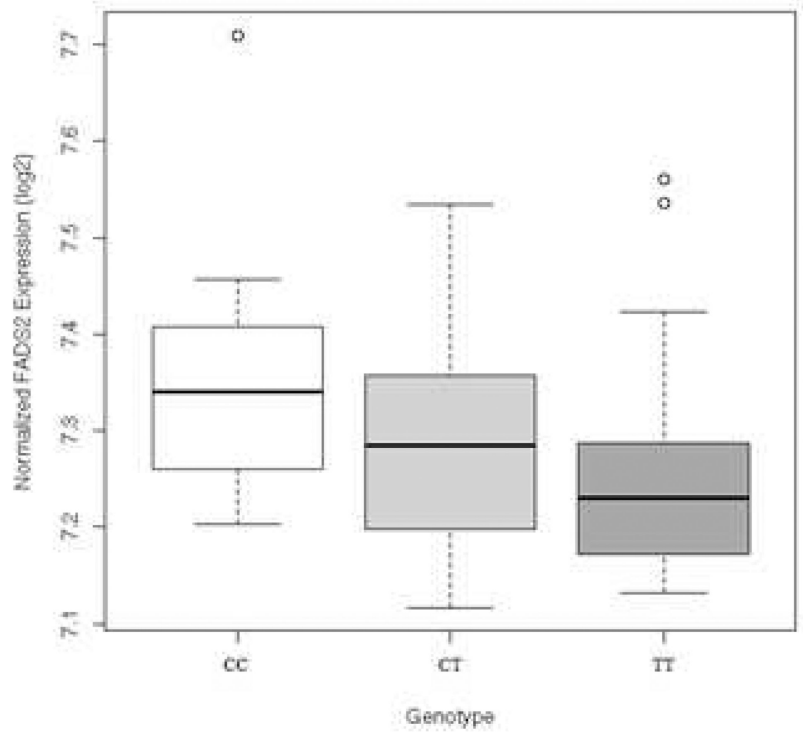

D. Association of rs11243081 with F13A1 expression

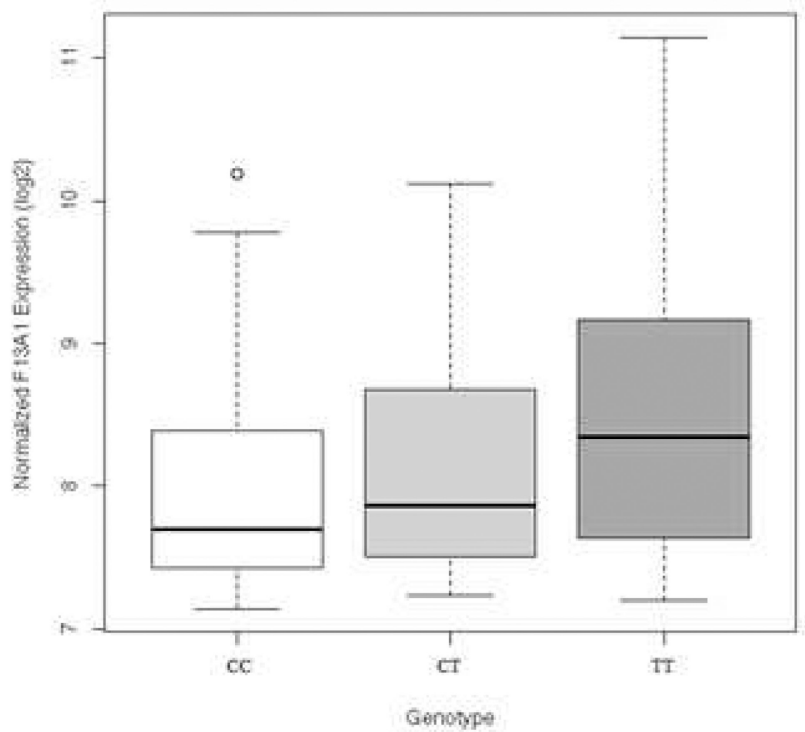

Figure 1.

Genome-wide significant expression quantitative trait loci (eQTLs) previously identified in CD4 positive lymphocytes of asthmatic subjects. A. Association of SNP rs4795405 with the expression of ORMDL3. B. Association of SNP rs174611 with FADS2 expression. C. Association of SNP rs2413669 with NAGA expression. D. Association of rs11243081 with F13A1 expression. 


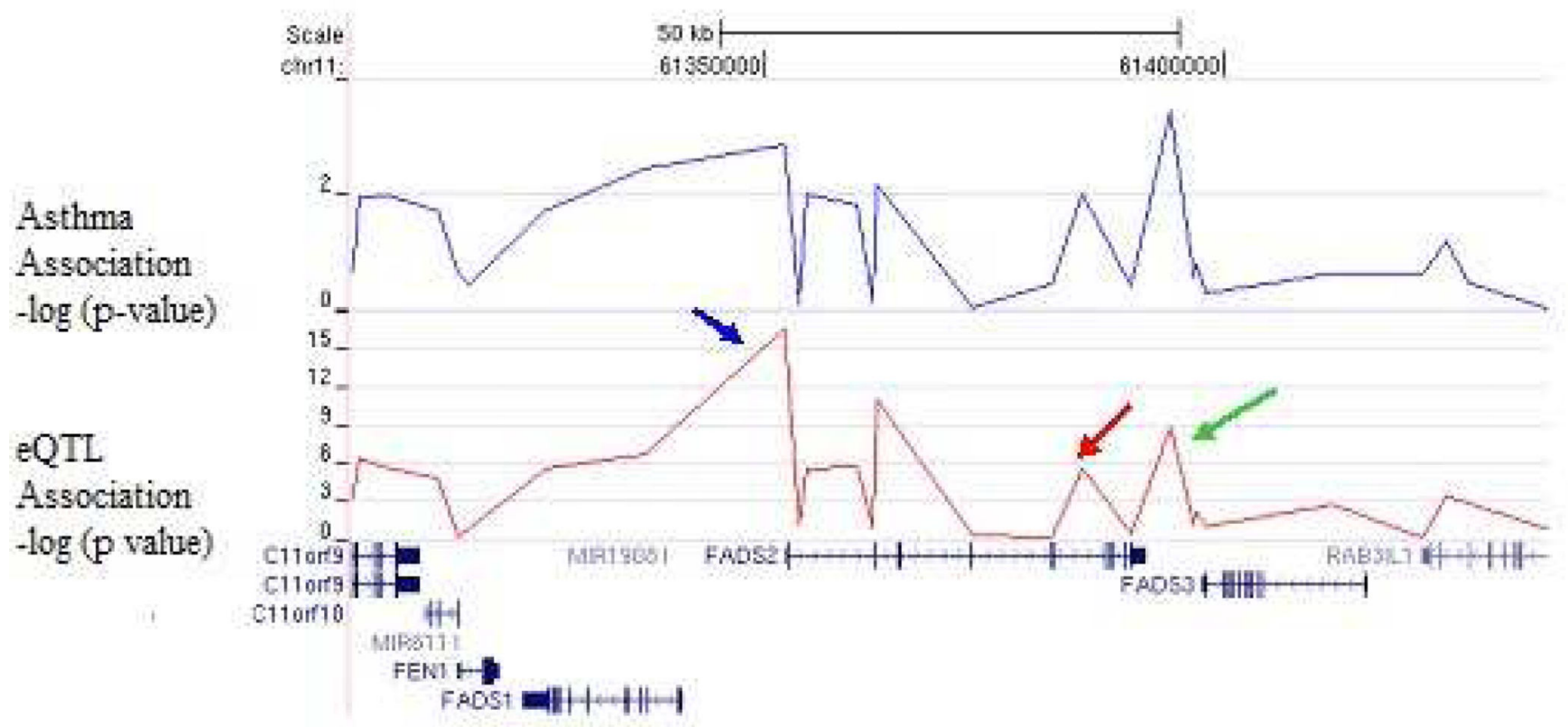

Figure 2. SNP-based eQTL analysis across the FADS2 locus SNP-based eQTL analysis across FADS2, demonstrating association of rs968567 with FADS2 expression ( $\mathrm{p}=10^{-15}, 30 \%$ expression variance explained). SNP rs968567 (blue arrow), located in a conserved region of the promoter, demonstrates association with FADS2 expression $\left(\mathrm{p}=10^{-15}\right)$. SNPs rs174627 (green arrow) and rs174611 (red arrow) are in LD with rs968567 and are associated with FADS2 expression and asthma susceptibility. 
a)

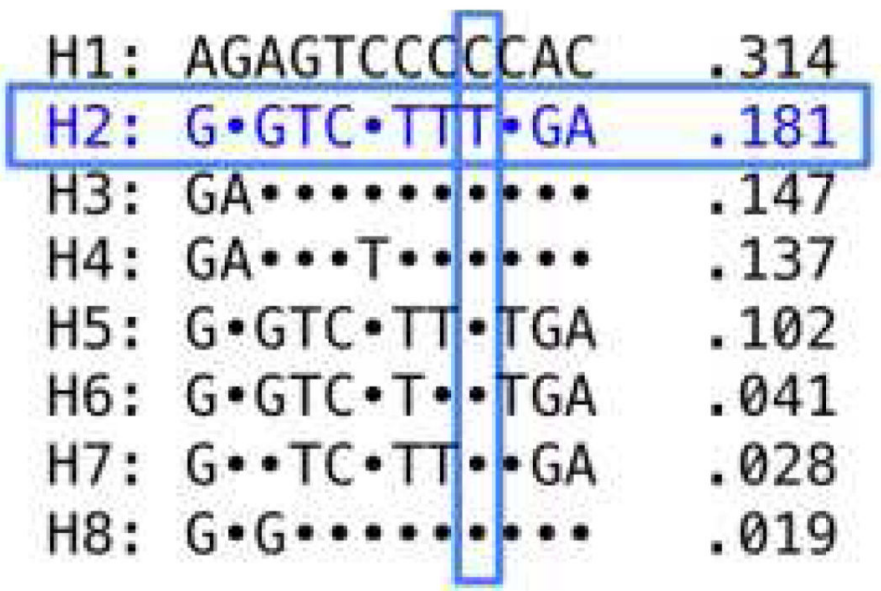

b)

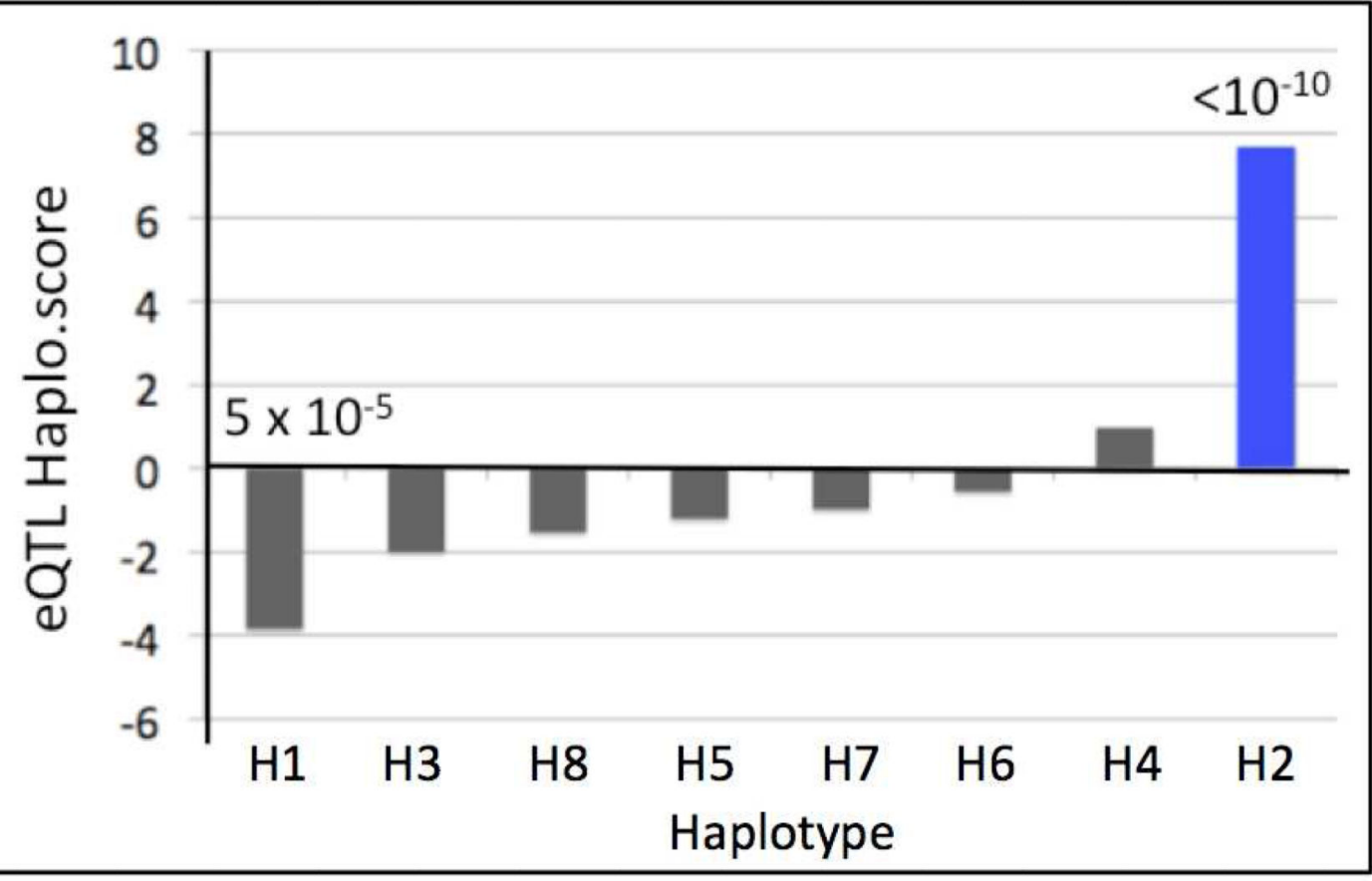

Figure 3. Haplotype analysis of the FADS2 locus

(a) Haplotype structure: Haplotype frequencies observed in at least 1\% of CAMP subjects are listed to the right of each haplotype sequence. Dots indicate the allele present in haplotype $\mathrm{H} 1$ - the most common haplotype. The asthma-associated rs $968567 \mathrm{~T}$ allele is unique to, and uniquely tags, haplotype 2 ( $\mathrm{H} 2$, boxed in blue), observed at $18.1 \%$ frequency. (b) Haplotype-based eQTL analysis: $\mathrm{H} 2$ demonstrates strong association with increased FADS2 expression $\left(\mathrm{p}<10^{-10}\right.$ ), while haplotype $1(\mathrm{H} 1$, frequency $31.4 \%)$ is associated with low FADS2 expression. Others (H3-H8) showed intermediate levels of FADS2 expression. 


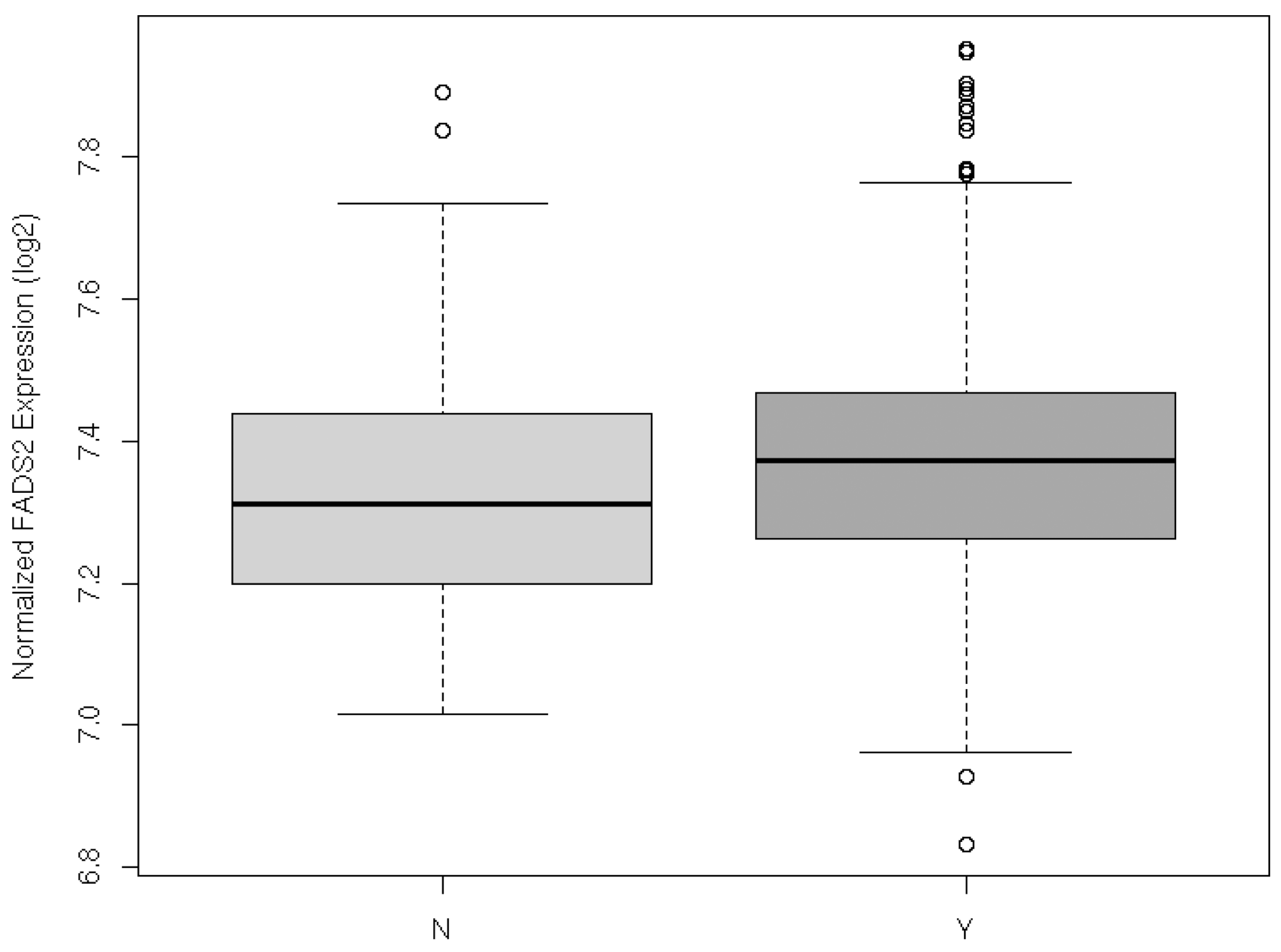

Asthma Diagnosis

Figure 4. Differential expression of FADS2 in asthmatic subjects compared to non-asthmatic controls in Asthma BRIDGE

Significantly increased expression of FADS2 in peripheral blood CD4+ lymphocytes of asthmatic subjects compared to non-asthmatic control subjects $(\mathrm{p}=0.003)$ 

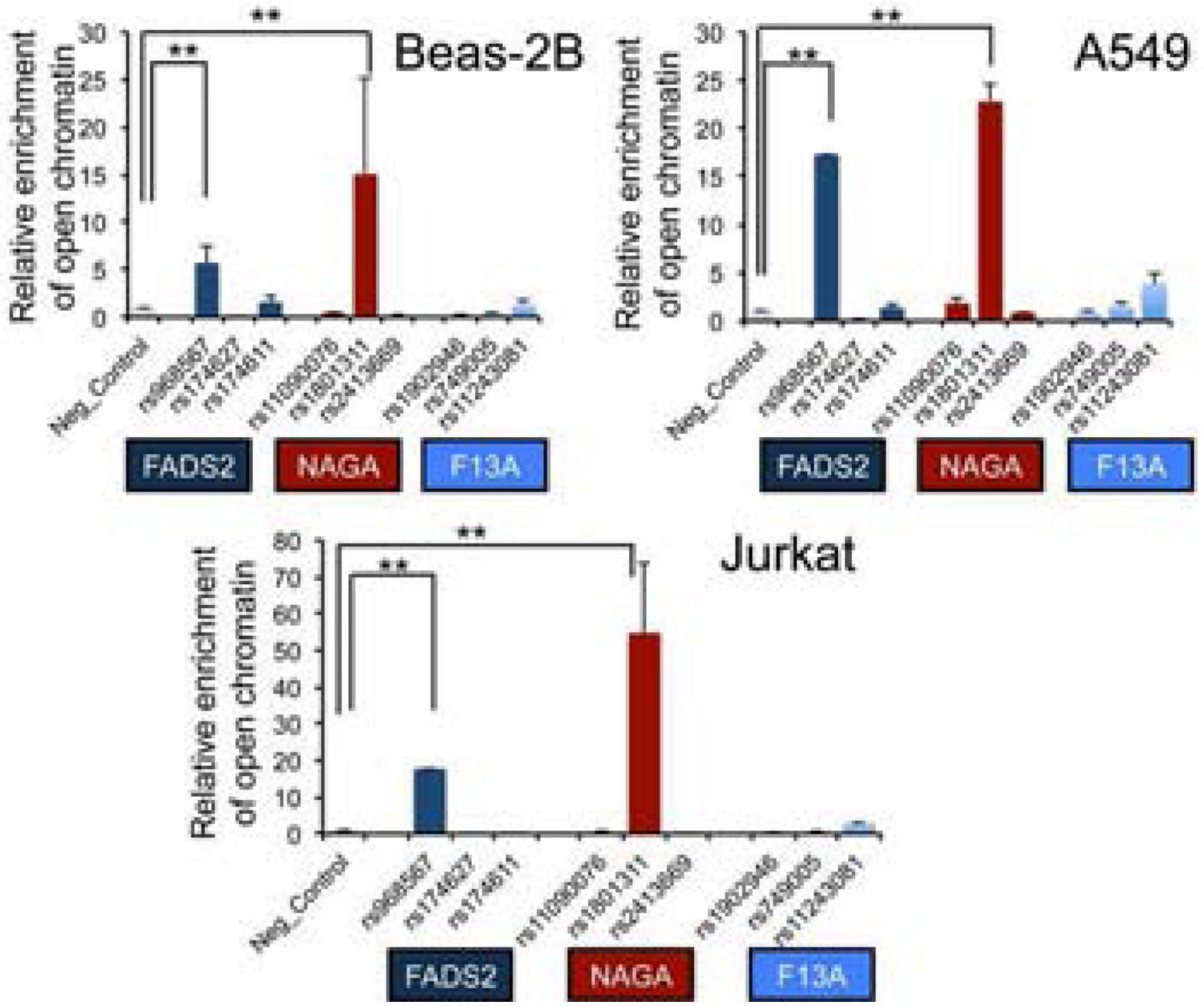

Figure 5. Functional annotation of the three asthma associated regions by FAIRE-PCR analysis Formaldehyde assisted isolation of regulatory enrichment (FAIRE) was performed at three association regions nearby FADS2, NAGA and F13A genes in Beas-2B, A549 and Jurkat cell lines by real-time PCR analysis. The graph depicts the relative FAIRE signal at each locus normalized to input and negative control regions. Each locus contains three SNPs nearby eQTL signals. Mean \pm SD are from two to four repeats for each SNP. **p<0.01 (unpaired one way $t$ test.) 


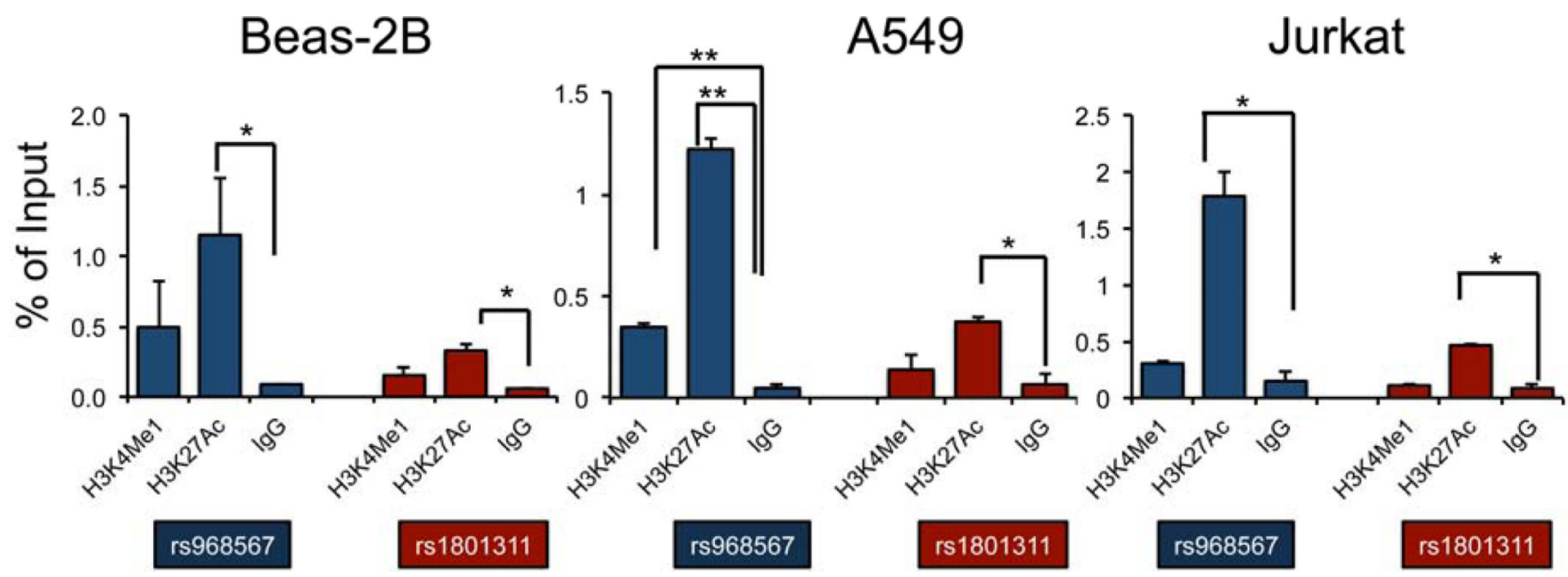

Figure 6. Enrichment of active histone marks in two asthma associated regions detected by ChIP-PCR analysis

Chromatin immunoprecipitation (ChIP) was performed using H3K4Me1 and H3K27Ac antibodies in Beas-2B, A549 and Jurkat cell lines targeting genomic regions nearby two SNPs rs968567 and rs1801311 in FADS2 and NAGA loci respectively. IgG was used as a negative control. The bars represent the average of a two biological replicates with standard deviations. * $\mathrm{p}<0.05 ; * * \mathrm{p}<0.01$ (paired one way $t$ test). 
Table 1

Baseline phenotypic characteristics of index children in CAMP and Costa Rica

\begin{tabular}{|c|c|c|}
\hline Variable & $\begin{array}{c}\text { CAMP } \\
\mathbf{n = 3 5 9}\end{array}$ & $\begin{array}{c}\text { Costa Rica } \\
\mathbf{n = 5 7 9}\end{array}$ \\
\hline Age (years) & $8.8(2.1)$ & $9.1(1.8)^{*}$ \\
\hline Female sex & $137(38 \%)$ & $222(41 \%)$ \\
\hline Height (cm) & $132.7(13.3)$ & $131.0(11.2)$ \\
\hline $\begin{array}{c}\text { Baseline pre-bronchodilator FEV } \\
\text { (L) }\end{array}$ & $1.6(0.5)$ & $1.7(0.5)$ \\
\hline $\begin{array}{c}\text { Baseline pre-bronchodilator } \\
\text { FEV }\end{array}$ / FVC (\%) & $79.1(8.3)$ & $82.6(7.2)$ \\
\hline \multirow{2}{*}{ Mean (standard deviation) or count (frequency) reported }
\end{tabular}


$\overline{0}$

ฮ

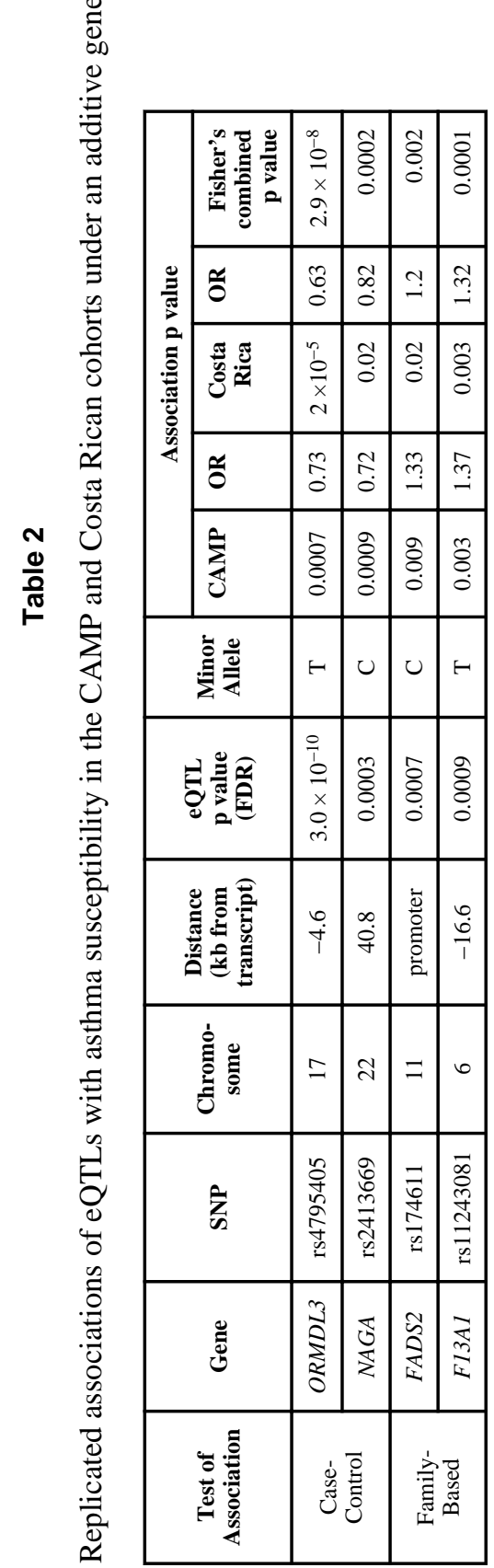

J Allergy Clin Immunol. Author manuscript; available in PMC 2015 November 01. 